\title{
Cultural Determinants of Learning Style Preferences
}

\author{
DIRK HOLTBRÜGGE \\ University of Erlangen-Nuremberg \\ ALEXANDER T. MOHR \\ University of Kent
}

\begin{abstract}
We investigate the relationship between cultural values and the learning style preferences of students of business administration. By linking Kolb's (1984) model of learning style preferences to the cultural values of learners we develop hypotheses that are tested against data collected from 939 individuals studying at universities in Germany, the UK, the USA, Russia, Ireland, Spain, the Netherlands, Poland, China, and the United Arab Emirates. Our findings show that learning style preferences vary with individuals' cultural values. We also find that study level, exchange student status, and gender are related to individuals' learning style preferences. The results are of importance to researchers and practitioners interested in the learning process of individuals from different cultural backgrounds.
\end{abstract}

\section{PROBLEM AND OBJECTIVES}

Understanding the learning style preferences of individuals from different cultural backgrounds is of growing importance in higher education for a number of reasons. In many countries, the number of foreign students enrolled at university has increased over the last decade, and this export of higher education services has become an important financial pillar for many of these countries. Despite more restrictive regulations on student visas, the number of foreign students in the United States has increased by $6 \%$ since 2001, and in 2007 there were almost 600,000 foreign students studying in the United States (Schworm, 2008). According to the UK Higher Education Statistics Agency (HESA) the number of foreign students in the United Kingdom has increased by more than $6 \%$ to over 300,000 from 2005-2006 to 2006-2007 (HESA, 2008). The number of foreign students in Germany has increased by $30 \%$ in the same period, and the 246,369 foreign students enrolled in German universities in 2007 accounted for $14.2 \%$ of all students (DAAD, 2008). A similar influx of foreign students has been recorded in other countries, such as France, Australia, and Japan (UNESCO, 2008). According to a recent report in the Economist ("Future is," 2009), almost 3 million individuals studied at universities outside their home countries in 2006. A particular increase has been recorded for the num- ber of Chinese students studying abroad, which was nearly 150,000 in 2007, and 200,000 were expected for 2008 (Ying, 2008). In 2002-2003 Chinese students were the largest group of foreign students in the UK and the second largest group in Germany (DAAD, 2008).

While English-speaking countries benefit from the spread of English as second language among students all over the world, non-English speaking developed countries have also seen an increase in the number of foreign students, partially due to the introduction of English language programs. Additionally, more and more universities have realized their dependency on the income generated from overseas students and have started tapping into overseas markets for higher education by offering distance-learning programs, collaborative programs with local universities abroad, or by opening overseas branches. Examples include US universities, such as Texas A\&M, Carnegie Mellon, or Cornell, all of which started to offer courses in Qatar in the early 2000s; French business school INSEAD's opening of an Asian campus in Singapore in 2000, and the establishment of an overseas campus in China by the University of Nottingham in 2005. Overall, these developments will continue to increase the cultural heterogeneity of universities' students in the future.

Widely accepted in the intercultural manage- 
ment literature is the notion that learning styles may vary from culture to culture (see, e.g., Abramson, Keating, \& Lane, 1996) and that universities need to rethink learning support services, modify curricula, and adjust teaching methods in order to enable all their students to achieve their learning objectives. To do this they have to be cognizant of how learning style preferences differ among students from different cultural backgrounds. Given the importance of this issue, it is surprising that only a small number of empirical studies can be found on this subject. In order to contribute to closing this gap, we empirically analyze the influence of cultural values on learning style preferences among 939 business students from 74 national backgrounds using the learning style classification suggested by Kolb (1984).

The remainder of our article is structured as follows: The ensuing section presents the learning style concept suggested by Kolb (1984), its key dimensions, as well as the associated classification of learners. The next develops hypotheses regarding the relationship between individuals' preferences for different learning styles and their cultural backgrounds. Following that, we explain the methodology and present the empirical data used for testing our hypotheses. The results of the empirical analysis and their implications for research and practitioners in higher education are then discussed. We conclude with a presentation of the limitations and some worthwhile extensions of the current study.

\section{LEARNING STYLES ACROSS (NATIONAL) CULTURES}

To date, very few studies have analyzed learning styles across cultures. While these studies have used various conceptualizations of learning styles (see, e.g., Jackson, 1995; Manikutty, Anuradha, \& Hansen, 2007; Ramburuth \& McCormick, 2001; Yamazaki \& Kayes, 2004; You \& Jia, 2008), the majority of investigations into how learning style preferences vary with individuals' cultural backgrounds has used the classification suggested by Kolb (1976, 1981b; 1984). These investigations include the studies by Auyeung and Sands (1996), Barmeyer (2004), Hanisch (2003), Jaju, Kwak, and Zinkhan (2002), Lam (1998), McKee, Mock, and Ruud (1992) and Yuen and Lee (1994). As we discuss below, these studies suffer from a number of shortcomings that we intend to address here.

Kolb's (1984) classification of learning styles is based on the assumption that individual learning can be conceptualized as a circular process consisting of four activity stages (see Figure 1). This learning cycle starts with a concrete experience. This experience is then reflected upon in the subsequent stage in which the individual learner thinks about possible ways to adequately respond to this situation (reflective observation). On this basis, the learner develops mental models to integrate and make sense of the experience (abstract conceptualization). These mental models are then used to make decisions and solve problems (active experimentation). The process results in further experiences and reflections on these experiences; that is, the process starts again.

Underlying this learning cycle are two dimensions, that Kolb (1984: 31) saw as necessary for learning: The first dimension "grasping" relates to the way in which information is acquired during the learning process (see vertical axis in Figure 1). Individuals acquire information either through concrete experience or through abstract conceptualization. Concrete experience stresses the involvement in experiences and feelings and emphasizes the singularity of specific situations (apprehension), while abstract conceptualization refers to theorizing about experience, using logic and concepts, and being concerned with elements common to many experiences in order to arrive at general theories (comprehension). The second dimension "transformation" relates to the way individuals handle information (horizontal axis in Figure 1). Kolb (1984) distinguishes between active experimentation, where the learner stresses practical applications-that is "doing" rather than "observing"-and reflective observation, where the

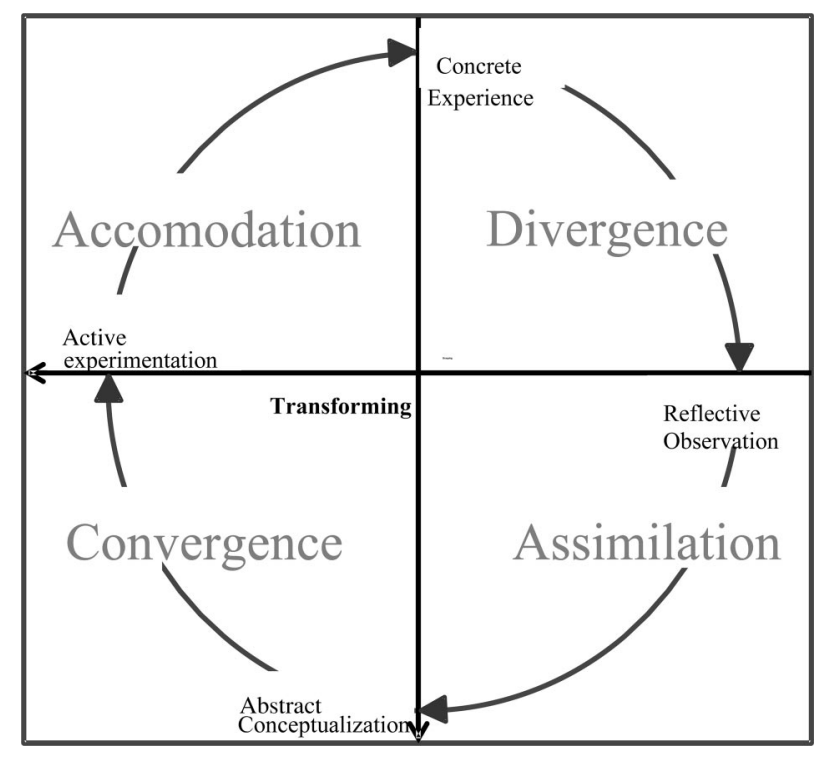

FIGURE 1

Learning Style Dimensions and Types (Adapted from Kolb, 1984) 
emphasis is on reflecting on specific experiences and understanding their meaning. Reflective observation emphasizes the use of information as a means to increase understanding instead of providing practical applications. Fundamental to Kolb's (1984) classification of learning styles is his observation that individuals do not use all the activities equally, but for each of the two dimensions, grasping and transformation, prefer and rely more on one of the respective activities. Thus, with regard to the "grasping" dimension, individuals will have a stronger preference for either concrete experimentation or abstract conceptualization. Regarding the "transformation" dimension, individuals prefer either active experimentation or reflective observation. Based on this preference for specific combinations of activities in their learning, Kolb (1984) proposed a learning style typology consisting of four distinct learning styles depending on the combination of learning activities preferred by individuals which correspond to the four quadrants in Figure 1.

A first learning style combines concrete experience with a preference for reflective observations when transforming acquired information. An individual combining these activities views experiences from different perspectives using divergent thinking and is thus labeled diverger. Divergers are seen as imaginative, emotional, peopleoriented, and culturally interested. The assimilator uses a combination of reflective observation and abstract conceptualization. Based on thorough observations, the assimilator is able to understand a situation through inductive reasoning and by developing an integrated explanation that combines the different pieces of information that are acquired. Assimilators are more interested in theories than in people or practical applications. Convergers combine abstract conceptualization with active experimentation. They apply their knowledge to examine problems and arrive at solutions in a hypothetic-deductive manner. The practical application of ideas is thus central to convergers, and working on technical problems is preferred to interacting with people. Accommodators prefer the combination of concrete experiences with active experimentation. They are good at implementing plans and adjust them to the situation as necessary. Accommodators are risk takers and solve problems intuitively, instead of relying on theories or mental models. If further information is needed, individuals with a preference for this learning style would ask other individuals rather than using their own analytical ability. Depending on the specific learning style preferences among a group of students, various authors (Kolb, 1984; Smith \&
Sadler-Smith, 2006) have presented various recommendations as to how pedagogical approaches should be adjusted. While the empirical evidence for the superiority of this matching is still ambiguous (Coffield, Moseley, Hall, \& Ecclestone, 2004), various authors have highlighted the potential negative causes of a mismatch (see, e.g., Kolb, 2000; Lawrence, 1997; Yamauchi, 1998).

Based on the expectation that individuals are the product of their cultural background and experiences, several studies have assumed that on individual's preferred learning style will depend on his or her cultural background. According to the empirical findings of McKee, Mock, and Ruud (1992), US students, for example, can be classified as accommodators. While these findings confirm the results of the earlier studies Baldwin and Reckers (1987), Baker, Simon, and Bazeli (1986), and Collins and Milliron (1987), they are in contrast to the findings of Jaju et al. (2002) who classified US students as divergers. The degree of ambiguity is even greater when one looks at the existing findings regarding the learning style preferences of Chinese individuals. In their comparison of learning styles of 632 accounting students in Australia, Hong Kong, and Taiwan, Auyeung and Sands (1996) find that Chinese students prefer abstract conceptualization and reflective observation. Whereas the study by Auyeung and Sands (1996) classified Chinese students as assimilators, a study by Lam (1998) based on data from 95 salespersons in Hong Kong shows that the majority of their sample could be classified as convergers or accommodators. While existing studies thus provide some support for differences in learning styles across national backgrounds of individuals, these findings remain ambiguous.

There may be a number of reasons for this ambiguity of existing research findings, including relatively small sample sizes or a lack of controlling for additional differences between individuals (e.g., age, professional experience). Yet, we would argue that the main explanation is the use of nation as a proxy for culture and the (implicit) assumption in all of these studies that "cultural values" are homogenous within "nation" states, an assumption that continues to be criticized (see, e.g., McSweeney, 2002b). Studies claiming to investigate the relationship between cultural values and learning style preferences regularly compare (average) learning styles between countries and ignore the heterogeneity of values among citizens of a nation. If one gives up this unrealistic assumption of within-country homogeneity of values, however, it is no longer surprising to find that studies using different samples within the same country 
lead to different results. By taking into account this within-country heterogeneity of values, our study contributes to our understanding of the influence of cultural values on individuals' learning style preferences by looking at commonly used cultural values from an individual perspective in order to overcome the "culture-equals-nation" approach characterizing much of the existing research.

\section{CULTURAL VALUES AND LEARNING STYLE PREFERENCES}

Based on the assumption that learning is culturebound (Abramson et al., 1996) we develop hypotheses that relate dimensions of culture to the likelihood that individuals prefer one learning style over another. While various concepts of culture can be found in research on cross-cultural management (see, e.g., Trompenaars, 1998), Hofstede's (2001) concept-despite being subject to criticism (see, e.g., Baskerville, 2003; McSweeney, 2002a, b) has become the most widely used concept of characterizing cultural values. While conceptual studies have discussed learning styles against the backdrop of different concepts of culture (see, e.g., Yamazaki, 2005), the existing empirical studies analyzing differences in learning style preferences across (national) cultures predominantly rely on this concept. The criticism leveled at Hofstede's concept ranges from methodological issues to the fact that his empirical data was collected over 30 years ago and may no longer reflect cultural values today. Our study addresses some of these issues by collecting new data on cultural dimensions from respondents, rather than relying on the data published by Hofstede (2001). A further problem associated with Hofstede's concept is the culture-equalsnation approach mentioned above, and that is common to research employing the concept of culture in a cross-national setting. In order to avoid this problem we look at cultural values as individual orientations rather than characteristics of nation states. Hofstede's (2001) concept of culture consists of five dimensions that are commonly regarded as useful for distinguishing between cultures. In the following, we link these five dimensions to preferences for specific learning styles, that is, the likelihood with which an individual prefers one of the four learning style types suggested by Kolb.

\section{Power Distance}

According to Hofstede (2001: 29), power distance relates to "different solutions to the basic problem of human inequality" and reflects the degree to which members of a culture accept or even expect hierarchical differences in social relationships. Related to the learning context, the overall argument is that individuals who accept or expect power distance in interpersonal interactions prefer those learning styles that allow them to maintain this power distance. Learning styles that reduce power distance are avoided as they might lead to socially undesirable situations. With regard to the grasping dimension of learning we suggest that abstract conceptualization is more suitable to maintaining power distance between learner and teacher. A number of authors have addressed the role of power distance for learning situations. Jaju, Kwak, and Zinkhan (2002: 52), for example, assert that "in high power distance cultures [students] are not expected to seek knowledge actively through their own experiences," while students in low power distance cultures would be expected to find their own "intellectual paths." In order to maintain the knowledge gap, and thus the power distance, the teacher is the main, if not the only source of information, and students accept information at face value without questioning the "power" of the teacher (Joy \& Kolb, 2009). Thus, the need for students to gather (their own) information through concrete experience is low, whereas the need to structure and make sense of the information being provided by the teacher is high, leading to a preference of students in high power distance cultures for abstract conceptualization. This is also in line with Barmeyer (2000: 75), who argues that individuals preferring concrete experience are more likely to engage in discussions and to seek feedback from peers while being less oriented toward their superiors. Based on these arguments we argue that power distance will increase individuals' preference for abstract conceptualization when it comes to the "grasping" of information (i.e., the vertical axis in Figure 1).

Regarding the transformation of information, that is the horizontal axis in Figure 1, we expect that high power distance will lead to more reflective observation as compared to active experimentation, based on the assumption that reflective observation is more conducive to maintaining power distance between teacher and learner. This prediction is based on the fact that the outcome of active experimentation may lead to outcomes that contradict or put into question the information that is being provided by the teacher, a situation that is socially undesirable and thus to be avoided. Reflective observation is unlikely to lead to such contradictions. Rather, reflective observation allows students (and teachers) to "maintain their power distance" and control over whether disagreement 
is made explicit. Students engaging in active experimentation and the associated autonomous learning reduce the need for a teacher, and we expect high power distance cultures to discourage active experimentation in order to maintain the competency differential between teacher and students. We thus argue that power distance raises individuals' preference for reflective observation as compared to active experimentation with regard to the "transformation" of information (i.e., the horizontal axis in Figure 1).

Overall, power distance is expected to increase individuals' preference for abstract conceptualization and reflective observation, which in Kolb's classification characterizes the assimilator learning style. We suggest that:

Hypothesis 1: There will be a positive association between power distance and the likelihood that individuals prefer a learning style that is characterized by high levels of abstract conceptualization and high levels of reflective observation, i.e., assimilation.

\section{Individualism/Collectivism}

Individualism is probably the dimension most frequently used to conceptualize differences between (national) cultures (see, e.g., Triandis, 1995). Hofstede (2001: 209ff.) defines individualism as the degree to which individuals are integrated into groups. In individualist societies the ties between individuals are loose, whereas the members of collectivist societies are integrated into strong ingroups which provide protection in exchange for loyalty. In individualist societies values such as independence and achievement of the individual are consequently seen as more important than collective values relating to the well-being of the group. Our general argument is that the preference of students with collectivist values for working or learning in groups is likely to have resulted in an enhanced ability to tap into the knowledge of others and thus a reduced need, inability, or even unwillingness to rely on concrete experience. This argument is supported by evidence from Kolb and Kolb (2005), who found empirical evidence that individuals with a preference for abstract conceptualization also prefer working in groups. Working with others may thus substitute the insights and information gained through concrete experience. Individualistic societies, on the other hand, believe in the individual's intellectual and affective autonomy (Joy \& Kolb, 2009). As a consequence, students with individualistic backgrounds may have come to rely more on concrete experience as a conse- quence of their reduced exposure to, and resulting inability or unwillingness to tap into collectives as sources of information. They will prefer those forms of learning for which input from and interaction with others are least important. We therefore expect that individualism is associated with a preference for concrete experience with regard to the "grasping" of information in Kolb's learning cycle (i.e., the vertical axis in Figure 1).

With regard to the transformation of information there does not seem to be a compeling argument for the influence of individualism on students' preferences for either active experimentation (AE) or reflective observation (RO). Although Joy and Kolb (2009) suggest a preference for reflective observation in collectivist cultures, this hypothesis is not supported by their data. Overall, we thus suggest: Hypothesis 2: There will be a positive association between individuals' individualism and their preference for a learning style characterized by abstract conceptualization, i.e., assimilation or convergence.

\section{Masculinity}

Hofstede (2001: 279) characterizes masculine societies by the dominance of "ego goals" such as achievement, competition, and assertive behavior over social, feminine values, such as cooperation and modesty. Within a learning context we would expect a preference for those learning styles that better cater to or reflect these values. With regard to the grasping dimensions, that is, the vertical dimension in Figure 1, concrete experience focuses on "feeling," whereas abstract conceptualization is associated with "thinking" as a source of information (Kolb 1984). Kolb and Kolb (2005) state that individuals preferring concrete experience are also "interested in people, tend to be imaginative and emotional, [and] have broad cultural interests" (Kolb \& Kolb, 2005: 196), which would point toward a dominance of feminine values. A preference for concrete experience is also associated with high levels of empathy in interpersonal interaction, and feelings are on important element in decision making (Barmeyer, 2000). Based on the above arguments we expect masculinity to be associated with a preference for abstract conceptualization.

The situation is similar with regard to the information transformation dimension of learning styles (horizontal axis in Figure 1), and we argue that reflective observation is more closely associated with masculine values than active experimentation. Jaju et al. (2002: 53) maintain that "masculine societies prefer concrete and quantitative 
results, whereas feminine cultures view a problem as a fragmented picture with many solutions. In masculine cultures, the learning comes from the active and assertive role of the individual, whereas in feminine cultures, the learning comes from the reflective view and opinions of other members of the society (e.g., teachers, parents, peers)." They expect members of masculine societies to prefer active experimentation, although this prediction is not supported by their empirical data. While no information about significance levels is given, the feminine culture (Korea) in Jaju et al.'s (2002) sample shows a higher mean value for active experimentation than the masculine societies (US, India). Kolb and Kolb (2005: 196) claim that individuals with a preference for reflective observation, "are best at understanding a wide range of information and putting it into concise, logical form. [They] are less focused on people and more interested in ideas and abstract concepts," which is in line with the characteristics of a masculine society. We thus argue that feminine values are associated with a preference for active experimentation and masculine values are associated with a preference for reflective observation. Based on these arguments we formulate the following hypothesis:

Hypothesis 3: There will be a positive association between individuals' masculinity and their preference for a learning style characterized by abstract conceptualization and reflective observation, i.e., assimilation.

\section{Uncertainty Avoidance}

Uncertainty avoidance (UA) refers to the desire of the members of a society to avoid uncertain situations. It is related to the level of stress in a society in the face of an unknown future (Hofstede, 2001). Members of high uncertainty avoidance societies prefer clear structures and regulations that reduce the level of (perceived) uncertainty associated with new and unknown situations, whereas members of societies with low uncertainty avoidance are more willing to accept uncertainty and do not require or even reject strict rules and regulations. Applied to the learning context, we would thus argue that individuals that strive to avoid uncertainty will prefer learning styles that reduce or at least do not significantly increase the level of uncertainty experienced by the learner.

With regard to the grasping dimension, that is, the acquisition of information, we suggest that the level of uncertainty associated with concrete experience is higher than the level of uncertainty asso- ciated with abstract conceptualization because the likelihood of being faced and having to deal with new and uncertain situations is greater during concrete experience. This is also in line with the suggestion of Jaju et al. (2002: 53) that high uncertainty avoidance is associated with students' being "more comfortable with structured learning situations and concerned with concrete and right answers. Such cultures value the information and knowledge delivered by the instructor and consider it as the best explanation to the problem." Thus, individuals with a strong tendency to avoid uncertainty are more likely to prefer abstract concepts with one correct answer and reward accuracy (Joy \& Kolb, 2009) than concrete experience with a wide variety of potential outcomes and interpretations. With regard to the grasping dimension of Kolb's framework, we thus expect high uncertainty avoidance to be related to a preference for abstract conceptualization.

Regarding the transforming dimension (i.e., the horizontal axis in Figure 1), we expect individuals with high levels of uncertainty avoidance to prefer reflective observation, as it is associated with comparatively lower levels of uncertainty. As reflective observation is, in our opinion, associated with lower levels of uncertainty than active experimentation, we expect individuals with high levels of UA to have a preference for reflective observation. More specifically, although both active experimentation and reflective observation allow for a reduction in the level of uncertainty associated with the acquired information, the outcomes of active experimentation are less predictable and thus create additional uncertainty that individuals with high UA prefer to avoid. In line with this, Kolb (1984) suggests that active experimentation involves risk taking, and Jaju et al. (2002) argue that "low uncertainty avoidance societies [... ] seek to take risks and find solutions by actively experimenting with the problems." Given these characteristics, we would thus expect individuals with a high UA orientation to avoid active experimentation because it is associated with a greater degree of uncertainty for the learner as compared to reflective observation. Instead, these individuals are more likely expected to prefer reflective observation where they can analyze the situation, gather more information, and reflect from a "safe" distance until the situation has become less uncertain. This is supported by Yamazaki (2005), who highlights the similarity between uncertainty avoidance and reflective observation. Additionally, Barmeyer (2000) suggests that individuals preferring reflective observation show a careful and reflecting approach 
to new things, which is more in line with high uncertainty avoidance. We thus suggest:

Hypothesis 4: There will be a positive association between uncertainty avoidance and the likelihood that individuals prefer a learning style characterized by abstract conceptualization and reflective observation, i.e., assimilation.

\section{Long-Term Orientation}

While Hofstede's (2001) original concept consisted of the four above-mentioned dimensions, he added the dimension "long-term orientation" in response to Hong Kong-based researchers who suggested that the four original dimensions were insufficient to capture the specific long-term orientation which they see as a particular characteristic of the Chinese culture. Long-term oriented societies are regarded as putting particular emphasis on values that are related to the future, such as, for example, perseverance and thrift (Hofstede, 2001). At the same time, history is important in societies with a long-term orientation. For example, in China (the country with the highest value for this cultural dimension), references to the past are omnipresent. With regard to learning style preferences we argue that long-term orientation will be positively associated with concrete experience. History is present in a very concrete form such as architecture, language, and works of art. Thus, individuals in these countries are accustomed to value past experiences and to reflect about them. Short-term orientation, on the other hand, is argued to be associated with active experimentation. Experiments lead to quick results and enable trial-and-error behavior. Based on these considerations we suggest the following hypothesis.

Hypothesis 5: There will be a positive association between long-term orientation and the likelihood that individuals prefer a learning style that is characterized by concrete experience and reflective observation, i.e., divergence.

\section{Control Variables}

While only a small number of studies have analyzed the differences of learning style preferences across (national) cultures, most studies have investigated the importance of a number of demographic factors, such as, for example, gender or age of individuals, for explaining variations in individual learning style preferences. Although the existing empirical findings on the role of these factors remain ambiguous, the theoretical ration- ales behind influences of these factors on learning style preferences seem convincing enough to include them as control variables into our study design. In line with existing studies on learning style preference of individuals we included age (Mainemelis, Boyatzis, \& Kolb, 2002; McKee et al., 1992); level of study (i.e., undergraduate vs. postgraduate; Mainemelis et al., 2002; McKee et al., 1992); and gender (Auyeung \& Sands, 1996; Barmeyer, 2000; Kayes, 2005; Mainemelis et al., 2002; McKee et al., 1992). Additionally, Kolb (1984) suggests that learning style preference may depend on factors, such as educational specialization, career choice, and current job role and tasks. As the individuals in our sample were quite homogeneous with regard to the educational specialization, career choice, and current job role and tasks, we collected information on individuals' professional experience. Finally, as our sample contains quite a large number of exchange students, we take into account whether the student is an exchange student, that is, foreign at the place of study at the time of the survey.

\section{SAMPLE AND MEASURES}

In order to test our hypotheses, questionnaires were distributed to students of business administration at universities in Germany, the UK, the USA, Russia, the Netherlands, Poland, China, and the United Arab Emirates (UAE). Since all students were enrolled in programs that were taught in English, we assumed a good level of English proficiency among respondents and used an English language questionnaire at all locations. Questionnaires were administered and collected during regular class room time in classes taught by the authors or colleagues at the authors' institutions who were briefed as to the content and purpose of the survey.

In total, we collected questionnaires from 1,044 individuals over the period 2007-2008. A number of questionnaires (105) were not included in our subsequent analysis, as relevant parts of the questionnaires were not filled in, or not filled in correctly. This was the case in particular for the items used to measure Kolb's learning styles which required respondents to rank optional sentence endings (see below). After eliminating questionnaires that were not filled in correctly we had responses from 939 individuals that could be used for empirical analyses. The students in the sample come from 74 countries with a majority of $39.7 \%$ being German, followed by British (9.5\%), and Indian (9.4\%) students. Almost half of the students (393 students or $41.9 \%$ ) were classified as exchange students, that 
is, students that were foreigners in their current country of residence. The age of respondents ranged from 17 years to 50 years, with 25 years as the average age of respondents. There were 507 (54\%) male and 432 (46\%) female students in our sample. Four hundred fifty-three $(48.2 \%)$ of the respondents had at least 1 year of professional experience, and the average length of professional experience among these respondents was 5 years. Four hundred ninety-three (52.5\%) of the individuals were enrolled in undergraduate (UG) programs, while 446 (47.5\%) studied for a postgraduate (PG) degree.

In order to investigate respondents' learning style preferences, we used Kolb's learning style framework, which has repeatedly shown to be useful and valid in this regard (Carlsson, Keane, \& Martin, 1976; Katz, 1988; Kayes, 2005; Kolb, 1976; Kolb, 198la; Kolb, 1984; Kolb, Rubin, \& McIntyre, 1984). In order to measure the four dimensions of Kolb's fromework we use the Learning Style Inventory (LSI). This was originally developed by Kolb (1976), and after concerns were raised regarding the low internal consistency of scales (see, e.g., Sewell, 1986), Kolb and colleagues presented a revised LSI in which short phrases substituted the original single word responses in order to increase its reliability. Since then there has been a third modification of the instrument, which further increased its validity and reliability (Mainemelis et al., 2002). The LSI consists of a number of sentences and four optional endings for each sentence that respondents rank in line with their preferences. Through combination of the scores for sentence endings the researcher calculates scores for concrete experience, reflective observation, abstract conceptualization, and active experimentation. These scores are then used to classify individuals into one of the four learning styles-accommodator, diverger, converger, or assimilator, explained above (see Figure 1). Table 1 shows the allocation of our 939 respondents into the four learning style types.

In order to measure cultural values we used the

TABLE 1

Learning Style Preferences

\begin{tabular}{lcc}
\hline Learning Style Preference & $\boldsymbol{N}$ & Percentage \\
\hline Accommodation & 231 & $24.6 \%$ \\
Divergence & 175 & $18.6 \%$ \\
Assimilation & 211 & $22.5 \%$ \\
Convergence & 322 & $34.3 \%$ \\
Total & 939 & $100.0 \%$ \\
\hline
\end{tabular}

$(\boldsymbol{N}=939)$
VSM94 ${ }^{1}$ instrument, suggested by Hofstede (1994, 2001), which has been used in existing research on cultural values (see, e.g., Thomas \& Bendixen, 2000). Given the above-mentioned problems with the culture-equals-nation approach, we used items contained in the VSM94 to calculate individuallevel cultural values. However, as the VSM94 has been developed to compare the mean values between countries, the guidelines accompanying the VSM94 with regard to the combination of items into the five dimensions could not be used. Instead, we carried out a principal component analysis of the VSM94 items. The Kaiser-Mayer-Olkin (KMO) measure of sampling adequacy fell into the "meritorious" band (0.831). This analysis resulted in a 6factor solution, and in checking the items loading onto the factors, we found that five factors with on Eigenvalue greater than 1 could be interpreted in line with Hofstede's five dimensions. The items that did not clearly load onto one of the five factors were dropped, but there was no case in which an item was used to measure a cultural dimension other than that suggested by Hofstede. The result was thus a mere reduction of the number of items used to measure each of the dimensions. Thus, the constructs should be interpreted in the same way as in other studies that have used them. In order to measure our control variables, the questionnaire included questions about students' age, study level (coded 0 for undergraduate and 1 for postgraduate level); whether they were an exchange student (coded 0 for local student and 1 for exchange student); gender (coded 0 for male and 1 for female students); and years of professional experience.

\section{RESULTS AND DISCUSSION}

Studies investigating learning style preference across cultures usually employ the culture-equalsnation approach, and thus, compare preferences for the different learning activities, for example, reflective observation, between individuals from different national backgrounds. While some authors merely provide mean values of learning style preferences in different "national cultures" without any indication of the statistical significance of these differences in mean values, other authors use $t$ tests of differences between mean values, MANOVA or multidimensional scaling to provide information about the statistical significance of

\footnotetext{
${ }^{1}$ Since carrying out this study, an updated version of this questionnaire (VSM08) has been made available (http://stuwww. uvt.nl/ csmeets/VSM08.html).
} 
the differences in learning styles between (national) cultures (see, e.g., Barmeyer, 2004; Jaju et al., 2002; Joy \& Kolb, 2009). Given the above-mentioned problems with this culture-equals-nation approach, that is, the assumption of within-nation homogeneity of values, we decided against combining individuals into categorical nationality groups. Instead, we focus on the individuals' values as measured by factors extracted from Hofstede's questions and use these as predictors of the likelihood to which individuals prefer one of the four learning styles suggested by Kolb. In order to investigate these relationships, we adopted multinomial logistic regressions (MLR). This approach is used to analyze the relationships between a categorical dependent variable with more than two categories on the one hand, and metric or dichotomous independent variables on the other hand. As learning style preference is a variable with four categories and our independent variables (cultural values, age, study level, exchange student status, gender) are metric or dichotomous, this approach was regarded as the most appropriate for investigating our hypotheses. In order to investigate the general importance of our independent variables we computed the likelihood ratio test, which evaluates the overall relationship between our independent variables and the allocation of individuals into one of the learning style types (see Table 2). ${ }^{2}$

The ratio of valid cases to independent variables in our study was 100.43 (939 divided by 9), which exceeded the recommended minimum ratio of 10 . Our sample thus meets this requirement for the use of multinomial logistic regression. The $\chi^{2}$ statistic used as the main measure of model fit was statistically significant $\left(\chi^{2}=58.603, D F=30, p \leq\right.$ .001). We also computed goodness-of-fit tests (Pearson, Deviance) in order to assess model quality. Adequate fit of the model is inferred from the nonsignificance of these tests, which was the case for our model (see Table 2). Since pseudo-R2 measures are not regarded as useful for MLR models, using classification accuracy is commonly regarded as a more appropriate indicator to assess their quality. Classification accuracy is a measure that is based on a comparison of predicted and actual group membership, that is, the allocation of an individual to one of the four learning style groups suggested by Kolb. The "proportional by chance" criterion used as benchmark for assessing the classification accuracy of our model accounts for

\footnotetext{
${ }^{2}$ We did not include professional experience in our model, as there was a very strong positive and statistically significant correlation between age and professional experience $(.853, p \leq$ $.001)$.
}

TABLE 2

Likelihood Ratio Tests

\begin{tabular}{|c|c|c|c|}
\hline & \multicolumn{3}{|c|}{ Likelihood Ratio Tests } \\
\hline & Chi-Square & $D F$ & Sig. \\
\hline Intercept & .000 & 0 & . \\
\hline \multicolumn{4}{|l|}{ Independent variables } \\
\hline Power Distance & 4.162 & 3 & .244 \\
\hline Individualism & 9.211 & 3 & .021 \\
\hline Masculinity & 11.486 & 3 & .009 \\
\hline Long-term & .783 & 3 & .854 \\
\hline \multicolumn{4}{|l|}{ Orientation } \\
\hline Uncertainty & .725 & 3 & .867 \\
\hline \multicolumn{4}{|l|}{ Avoidance } \\
\hline \multicolumn{4}{|l|}{ Control variables } \\
\hline Age & .605 & 3 & .895 \\
\hline Level of study & 7.246 & 3 & .040 \\
\hline Exchange student & 14.017 & 3 & .003 \\
\hline Gender & 7.131 & 3 & .048 \\
\hline \multicolumn{4}{|c|}{ Model $\chi^{2}(30 D F)=58.603^{* * *}$} \\
\hline \multicolumn{4}{|c|}{ Pearson $\chi^{2}(2778 D F)=2820.392$} \\
\hline \multicolumn{4}{|c|}{ Deviance $\chi^{2}(2778 D F)=2497.415$} \\
\hline \multicolumn{4}{|c|}{ Proportional chance criterion $=.14$. } \\
\hline Classification Acc & .371. & & \\
\hline
\end{tabular}

the fact that even if our independent variables had no influence on an individual's preference for one of the learning styles, the model's predictions of their learning style preference would still be correct some of the time. The proportional by chance criterion is computed by summing the squared percentages of students in each learning style category and is 0.14 for our sample. Since the classification accuracy of our model (0.37l) exceeds this proportional by chance criterion by more than the recommended $25 \%$, our model satisfies the criteria for classification accuracy and thus supports the general influence of our independent variables on the learning style preferences of the individuals in our sample.

Although the results shown in Table 2 indicate that there are statistically significant influences of individualism, masculinity, study level, exchange student status, and gender on individuals' learning style preferences, they give only a general indication of the relevance of our independent variables in explaining differences in individuals' learning style preferences. In order to investigate our specific hypotheses, Table 3 shows the parameter tests of our overall model. These parameter tests allow us to check if our independent variables play a statistically significant role in differentiating between individuals' preference for one of the four learning styles.

Standard errors (SE) exceeding a value of 2 indicate multicollinearity. As shown in Table 3, the 
TABLE 3

Multinomial Logistic Regression Model Predicting Membership of Individuals in Kolb's (1984) Learning Style Types

\begin{tabular}{|c|c|c|c|c|c|c|c|c|c|c|c|c|}
\hline & \multicolumn{2}{|c|}{ I } & \multicolumn{2}{|c|}{ II } & \multicolumn{2}{|c|}{ III } & \multicolumn{2}{|c|}{ IV } & \multicolumn{2}{|c|}{$\mathrm{V}$} & \multicolumn{2}{|c|}{ VI } \\
\hline & \multicolumn{2}{|c|}{ Ācc vs. Conv } & \multicolumn{2}{|c|}{ Div vs. Conv } & \multicolumn{2}{|c|}{ Āss vs. Conv } & \multicolumn{2}{|c|}{ Div vs. Acc } & \multicolumn{2}{|c|}{ Āss vs. Ācc } & \multicolumn{2}{|c|}{ Āss vs. Div } \\
\hline & $\boldsymbol{\beta}$ & $S E$ & $\boldsymbol{\beta}$ & $S E$ & $\boldsymbol{\beta}$ & $S E$ & $\boldsymbol{\beta}$ & $S E$ & $\boldsymbol{\beta}$ & $S E$ & $\boldsymbol{\beta}$ & $S E$ \\
\hline \multicolumn{13}{|l|}{ Independent variables } \\
\hline Masculinity & -.017 & .195 & $-.571^{* *}$ & .212 & $.555^{* *}$ & .196 & -.096 & .228 & $.574^{* *}$ & .215 & $.729 * *$ & .229 \\
\hline Uncertainty Avoidance & -.066 & .089 & -.061 & .097 & -.027 & .090 & .006 & .104 & .039 & .098 & .033 & .105 \\
\hline Long-term Orientation & -.113 & .150 & -.100 & .163 & -.319 & .224 & .013 & .176 & .000 & .167 & -.014 & .177 \\
\hline \multicolumn{13}{|l|}{ Control variables } \\
\hline Age & .000 & .020 & -.037 & .022 & .000 & .019 & -.037 & .024 & .000 & .021 & .036 & .024 \\
\hline Level of study $(=0)$ & $.421^{*}$ & .204 & -.116 & .221 & -.207 & .206 & $-.437^{*}$ & .239 & $-.528^{*}$ & .225 & -.091 & .240 \\
\hline
\end{tabular}

${ }^{*} p \leq .05 .{ }^{* *} p \leq .01 .{ }^{* * *} p \leq .001$.

Acc $=$ Accommodation; Conv $=$ Convergence; Div $=$ Divergence; Ass $=$ Assimilation .

Model $\chi^{2}(30 D F)=58.603^{* * *}$.

Pearson $\chi^{2}(2778 D F)=2820.392$

Deviance $\chi^{2}(2778 D F)=2497.415$.

standard errors for all of our independent variables are far below this value, which indicates that multicollinearity is not a problem. Multinomial logistic regressions consist of a series of embedded binary logistic comparisons, and the $\beta$ values in Table 3 reflect the respective independent variable's contribution to changing the odds of an individual being allocated into one learning style type as compared to a reference learning style set by the researcher. In order to obtain results for each possible combination of learning styles and investigate our hypotheses, we varied the reference category for these comparisons. In column I of Table 3, for example, the reference learning style was "Convergence" and the beta values indicate the influence of our variables on the likelihood that an individual is allocated to the "Accommodation" style rather than the "Convergence" learning style.

In our first hypothesis we suggested that power distance will increase an individual's likelihood to be classified as Assimilator. The results in Table 3 do not fully support this hypothesis. The B value for power distance in column III indicates that power distance has a positive and statistically significant effect $(.362, p \leq .05)$ on the likelihood that an individual prefers Assimilation over Convergence. Yet, while the results in columns V and VI indicate that power distance has a positive influence on an individual's preference for the Assimilator learning style over Accommodation (column V) and over Divergence (column VI), the respective coefficients are not statistically significant (.299, ns and .311, ns). There is thus support for the suggested role of power distance in increasing the likelihood of individuals' preferring assimilation only when compared to individuals' preference for convergence.

In Hypothesis 2 we suggested that individualism is positively associated with individuals' preference for either Assimilation or Convergence. The statistically significant coefficients in columns I and II (Table 3) provide empirical support for the positive effect of individualism on students' preference for Convergence. The dependent variable in column I is an individual's preference for Accommodation as compared to her/his preference for Convergence. The negative coefficient (-.556, $p \leq .01$ ) indicates that individualism reduces the preference for Accommodation over Convergence; in other words, individualism increases the preference for Convergence in line with our second hypothesis. Column II shows a similar result regarding individuals' preferences for Divergence over Convergence: Individualism increases students' preference for Convergence. The comparison of Assimilation and Convergence in column III shows that individualism does not have a significant influence on students' preference for Assimilation over Convergence. As our hypothesis suggested a positive influence of individualism on students' preference for either of these two learning styles, this result supports our hypothesis. With regard to the influence of individualism on students' prefer- 
ence for Assimilation as compared to Accommodation (column V) and compared to Divergence (column VI), however, the respective $\beta$ values are not statistically significant. There is thus support for Hypothesis 2 with regard to the positive influence of individualism on students' preference for Convergence, that is, a learning style that is characterized by active experimentation and active abstract conceptualization.

In Hypothesis 3 we argued that masculinity would increase the likelihood of students' preferring an Assimilator learning style. This is borne out by the positive and statistically significant coefficients in columns III, V, and VI in Table 3 which reflect the influence of masculinity on an individual's preference for Assimilation compared to the other three learning styles. There is also a statistically significant influence of masculinity on the odds that individuals prefer Convergence over Divergence (column II, $-.571, p \leq .01$ ). However, as column III indicates a positive influence of masculinity on students' preference for Assimilation over Convergence, this result does not conflict with the main findings that support Hypothesis 3.

Our results do not provide any empirical support for Hypotheses 4 and 5. While Hypothesis 4 suggested that uncertainty avoidance would lead to a preference for Assimilation, Hypothesis 5 suggested that individuals' preference for Divergence in their learning would increase with long-term orientation. Yet, none of the coefficients for either cultural dimension is statistically significant in columns I to VI in Table 3. A possible explanation for the lack of support of Hypothesis 4 may be the existence of a U-shaped relationship between the two cultural dimensions and the preferred learning style. It could be argued that individuals with a strong desire to avoid uncertainty prefer abstract conceptualization, as this allows for a reduction in uncertainty. At the same time, however, individuals with a very weak desire to avoid uncertainty might also prefer this learning style because abstract concepts may be adapted in a very flexible way to new and unknown situations. Thus, individuals on the extreme poles of this cultural dimension may be guided by two different ideals that both favor abstract conceptualization: "The members of cultures that fall in between may be relying on concrete experiences as well to learn since they are not overburdened with ideals" (Joy \& Kolb, 2008: 81). The explanation might be similar for the lack of a significant linear relationship between long-term orientation and learning style preferences in our findings.

With regard to the included control variables, there are a number of statistically significant co- efficients indicating influences on learning style preferences (see Table 3). We included "age" as this variable has been suggested to influence learning style preferences (see, e.g., Kayes, 2005). Yet, similar to the results of existing studies, such as, for example, Auyeung and Sands (1996) or Mainemelis et al. (2002), we did not find any significant difference in learning style preferences based on age. Age does not appear to be of importonce for an individual's choice of learning style given the lack of statistically significant effects for this variable.

With regard to the "level of study," that is, whether students studied at the undergraduate or postgraduate level, Kayes (2005) found higher scores for abstract conceptualization among graduate students than undergraduate business students. However, the PG students in his sample were employed full time, and he suggests that differences may have been due to the work demands faced by PG students. Based on this finding we tested for differences in the learning style preferences between UG and PG students. The results of our study indicate that students studying for an undergraduate degree are more likely to prefer Accommodation over Convergence (column I), over Divergence (column IV) and over Assimilation (column V; see Table 3). All of the respective coefficients are statistically significant. In turn, this implies that students studying on the postgraduate degree are more likely to prefer any of these latter learning styles over Accommodation. Our results are in line with Kayes' (2005) findings that abstract conceptualization scores for PG students were higher than for UG students, indicating a preference of PG students for either Convergence or Assimilation.

The results regarding the influence of the "exchange status of the student," that is, whether the student was a local or an exchange student, show that local students are more likely to prefer Convergence over Divergence (column II, $-.643, p \leq$ 01), Accommodation over Divergence (column IV, $-.742, p \leq .01$ ), and Assimilation over Divergence (column VI, .471, $p \leq$.05). In other words, local students are significantly less likely than exchange students to prefer a Divergence learning style. There seems to be a preference of exchange students for a Divergence learning style, which is characterized by concrete experience (on the grasping dimension) and reflective observation (on the transformation dimension). The results indicate that exchange students have a higher preference for concrete experience over abstract conceptualization than their local fellow students. This seems plausible in as for as studying in a foreign 
country can be seen as a manifestation of this concrete experience in acquiring new information as opposed to learning about a foreign culture from one's home country through abstract conceptualization. At the same time, however, our results indicate that exchange students prefer reflective observation to active experimentation when it comes to the transformation of the acquired information. Reflective observation may be more suitable for helping exchange students in making sense of newly acquired information by relating it to previous experiences in their home country.

Finally, our results for the "gender" control variable shows that male students are likely to prefer Convergence over Accommodation (column I), Divergence over Accommodation (column IV), as well as Assimilation over Accommodation (column V). In turn, this implies that female students are more likely than their male counterparts to prefer Accommodation (active experimentation/concrete experience) in their learning. While existing studies have not detected any evidence for gender effects on preferences with regard to information processing (see, e.g., Auyeung \& Sands, 1996; Kayes, 2005), Mainemelis et al. (2002) found that male learners have a significantly stronger preference than female learners for conceptualizing when acquiring information as part of their learning. This is in line with the findings of our study.

We also intended to control for "professional experience" of the participants. However, due to the strong correlation of this factor with age, we did not include this variable in our model in order to avoid multicollinearity. Given the strong correlation between individuals' professional experience and their age in addition to the absence of a statistically significant influence of age on learning style preferences, we suggest that our findings are in line with McKee, Mock, and Ruud (1992) who found no empirical evidence for an influence of professional experience on learning style preferences.

\section{CONTRIBUTIONS, LIMITATIONS, AND IMPLICATIONS FOR FUTURE STUDIES}

By analyzing the relationship between cultural values and learning style preferences of 939 students, our study contributes to research and practice in several ways. Avoiding the problems associated with the culture-equals-nation approach, we provide evidence that cultural values are related to learning style preferences of students. In particular, the study reveals a positive influence of individualism on the odds that learners prefer a learning style characterized by active experimen- tation and abstract conceptualization, that is, Convergence. Masculinity was found to have a positive effect on the likelihood that learners prefer $a$ learning style characterized by abstract conceptualization and reflective observation, that is, Assimilation. The study provides no clear-cut evidence for an influence of Power Distance, Long-Term Orientation, or Uncertainty Avoidance. Taking into account a range of control variables, the study also provides empirical evidence for differences in learning style preferences between undergraduate and postgraduate students, between male and female students, and between exchange and local students.

Although not all of our hypotheses are supported by the data, the findings are of importance for practice in a number of ways. First, the possibility that the learning style preferences of an individual depend on his or her cultural background puts into question the potential for, and the desirability of convergence of education systems which-in Europe-has been triggered by the Bologna declaration. ${ }^{3}$ If individuals from different cultural backgrounds have different learning style preferences, a one-size-fits-all model might be unlikely to help students achieve the required learning outcomes.

A second implication relates to the growing cultural diversity of student cohorts. International exchange programs, the provision of training and teaching activities in countries with different cultural backgrounds, and the worldwide recruiting of students lead to culturally diverse student cohorts in which individuals may differ significantly with regard to their preferred learning styles, rendering pedagogical approaches geared toward single learning styles ineffective. Instead, educators may develop "toolboxes" (Adey, Fairbrother, \& Wiliam, 1999) of approaches to teaching in order to enhance the cultural compatibility between learner and the learning environment (Yamauchi, 1998).

Large universities might consider splitting student cohorts and employing different pedagogical methods reflecting different learning styles of subgroups. However, we would caution against such an approach on the grounds that although individuals may show a preference for a specific learning style, most research shows that students are often multimodal (Peters, Jones, \& Peters, 2008). Such an approach would also prevent students from benefiting from a diverse learning environment, which in itself contributes to the students' learning expe-

\footnotetext{
${ }^{3}$ The Bologna declaration is a pledge by 29 countries in Europe to reform the structures of their higher education systems in $a$ convergent way in order to increase student mobility across borders.
} 
riences. Our results also highlight the need to increase learners' and teachers' awareness of the influence of cultural values on learning style preference in order to improve their own learning in the sense of metacognition (Antonietti, 1999). This awareness of the effects of cultural values on one's own and other's learning styles may be enhanced through discussion about learning styles, and might improve learning in group work situations in which students are made aware of existing differences in learning styles and are enabled to build on these differences in a synergistic way in order to enhance the overall learning experience of the group.

There are a number of limitations that need to be taken into account when interpreting the results of this study. A first limitation relates to our choice of independent variables. Although the classification accuracy of our MLR is significantly above the proportional chance criterion, further increases may be possible by including additional variables. Kolb (1984), for example, suggests that learning style preference may depend on personality type, pointing toward interesting extensions that integrate additional insights from personality psychology (see, e.g., McAdams \& Pals, 2006) into the investigation of learning styles. Including personality types, as for example, conceptualized through the Myers-Briggs Type Indicator (MBTI; Myers, McCaulley, Quenk, \& Hammer, 2000) or Keirsey's (1998) temperament sorter may increase the predictive accuracy of the model further. However, such attempts need to take into account the potential overlaps that exist between the personality types as suggested, for example, by Keirsey (1998), and the learning style types suggested by Kolb. ${ }^{4}$ Additional variables that have been suggested to affect learning style preferences include their year at university (Auyeung \& Sands, 1996), whether students were full-time or part-time students (Mainemelis et al., 2002), discipline (Kolb \& Kolb, 2005), or differences in education systems (McKee et al., 1992). Whereas neither Auyeung and Sands (1996) nor Mainemelis et al. (2002) found empirical support for the respective variable, research trying to take into account institutional differences between students' home countries struggles with adequately conceptualizing these differences. There is also a debate on how far learning style preference is a "fixed trait or dynamic state" (Kolb \& Kolb, 2005: 199). While level of study may be regarded as

\footnotetext{
${ }^{4}$ We would like to thank one of the anonymous reviewers for highlighting the importance of personality types as well as the overlaps that exist between these concepts and Kolb's concept.
}

a proxy for changes in learning styles over time, this admittedly is a very rough approximation, and future research may be able to provide longitudinal data on this development. Finally, it has to be noted that we discussed and investigated the role of each individual cultural dimension in isolation from the others, yet it may be the case that preferences for specific learning style are determined by combinations or configurations of cultural facets. ${ }^{5}$

A second set of limitations relates to the ways of measuring the key variables in this study. First, the LSI has been criticized for having limited testretest reliability (see, e.g., Freedman \& Stumpf, 1978). This means that there can be significant unexplained variation in the four learning measures when an individual subject is tested and retested after a short period of time (McKee et al., 1992). This criticism, however, has been made about several other widely used learning style instruments as well, and is, therefore, probably a characteristic shared by many cognitive style instruments (Sewell, 1986). Related to this concern is the relatively low internal consistency of the LSI scales. Nunnally (1978) recommends that only itembatteries with Cronbach's alpha of .50 and above should be used for hypotheses testing, which was the case in our study (CE .70, RO .67, AC .76, and AE .71). Yet, future studies may want to scrutinize Kolb's concept further by checking factorial invariance across different (sub-)groups of samples, similar to the analyses carried out by Duff (2002), who investigated the factorial invariance of the Revised Approaches to Studying Inventory and suggested differences in the measurement constructs for male and female students. Such analyses for Kolb's framework would increase confidence in the LSI. Future studies may also attempt to increase the reliability by translating the questions into the language of the participants (see, e.g., McKee et al., 1992). The issue of different languages has also been highlighted by McKee, Mock, and Ruud (1992: 336), who investigated the differences in learning styles between US-American and Norwegian students. They found that "Norwegian learning style preference measures obtained via a Norwegian language instrument were significantly different from those obtained via an English language instrument, even though the Norwegians were all judged to be fluent in English." The authors thus suggest caution when "interpreting the results from English language instruments administered

\footnotetext{
${ }^{5}$ We would like to thank one of the anonymous reviewers for pointing out this possibility.
} 
to foreign nationals, even where the subjects are fluent in English."

It also has to be borne in mind that the LSI gathers individuals' preferences for learning rather than their actual learning styles. While it may be assumed that there is a close relationship between these two variables, this cannot necessarily be taken as a given. Finding out about the actual learning styles used by students would require different methodological approaches and information not only from individuals, but potentially also from their teachers. Finally, one has to bear in mind that there exists a wide range of alternative learning style frameworks (for a detailed review of the most important concepts, see Coffield et al., 2004), that differ, for example, in the extent to which they take into account the emotional or biological underpinnings of learning (see, for example, Ledoux, 1999; Zull, 2002). ${ }^{6}$ Although Kolb's concept is one of most important learning style models, it has not escaped criticism, and using alternative concepts, such as those suggested, for example, by Entwistle, Hanley, and Hounsell (1979), Allinson and Hayes (1988), or Honey and Mumford (1992), may lead to additional insights into the influence of cultural values on learning style preferences.

With regard to the measurement of the cultural dimensions in our study, the used instrument (VSM94) has been criticized on various grounds (Kruger \& Roodt, 2003; Spector, Cooper, \& Sparks, 2001). While we have tried to minimize these problems by carrying out a principal component analysis of the items suggested by Hofstede (1980) in order to arrive at more reliable measures, there remains scope to improve measures of the respective dimensions. A more fundamental problem relates to the ability of catalogues of dimensions, such as the one proposed by Hofstede and other researchers (see, e.g., House, Hanges, Javidan, Dorfman, \& Gupta, 2004), to adequately capture the complexity and richness of cultural values. While it might be difficult to completely avoid such etic approaches when studying culture due to the need to maintain some degree of comparability, future research may attempt to complement them with emic approaches and the associated research designs (see, e.g., Morris, Leung, Ames, \& Lickel, 1999).

While existing studies have focused on the differences in individuals' learning style preferences and explaining such differences, further research

\footnotetext{
${ }^{6}$ We would like to thank one of the anonymous reviewers for pointing out this important issue.
}

is warranted into the consequences of learning styles in different learning situations and contexts. In particular, this study has revealed significant differences between local and exchange students. Given the increasing importance of international student exchanges, this aspect might be a very interesting alley for future studies.

\section{REFERENCES}

Abramson, N. R., Keating, R. J., \& Lane, H. W. 1996. Crossnational cognitive process differences: $\mathrm{A}$ comparison of Canadian, American and Japanese managers. Management International Review, 36(2): 123-147.

Adey, P., Fairbrother, R., \& Wiliam, D. 1999. Learning styles and strategies: A review of research. London: King's College, School of Education.

Allinson, C., \& Hayes, J. 1988. The Learning Styles Questionnaire: An alternative to Kolb's Inventory. Journal of Management Studies, 25(3): 269-281.

Antonietti, A. 1999. Can students predict when imagery will allow them to discover the problem solution? European Journal of Cognitive Psychology, 11(3): 407-428.

Auyeung, P., \& Sands, J. 1996. A cross cultural study of the learning styles of accounting students. Accounting and Finance, 36: 261-274.

Baker, R. E., Simon, J. R., \& Bazeli, F. P. 1986. An assessment of the learning style preferences of accounting majors. Issues in Accounting Education, 1(1): 1-12.

Baldwin, B. A., \& Reckers, P. M. 1987. Exploring the role of learning style research in accounting education policy. Journal of Accounting Education, 2(2): 281-292.

Barmeyer, C. I. 2000. Interkulturelles Management und Lernstile. Frankfurt/New York: Campus Verlag.

Barmeyer, C. I. 2004. Learning styles and their impact on crosscultural training: An international comparison in France, Germany and Quebec. International Journal of Intercultural Relations, 28(6): 577-594.

Baskerville, R. F. 2003. Hofstede never studied culture. Accounting, Organizations and Society, 28(1): 1-14.

Carlsson, B., Keane, P., \& Martin, J. B. 1976. R\&D organizations as learning systems. Sloan Management Review, 17(3): 1.

Coffield, F., Moseley, D., Hall, E., \& Ecclestone, K. 2004. Learning styles and pedagogy in post-16 learning. A systematic and critical review. London, UK: Learning and Skills Research Centre.

Collins, J. H., \& Milliron, V. C. 1987. A measure of professional accountants' learning styles. Issues in Accounting Education, 2(2): 193-206.

DAAD. 2008. Wissenschaft weltoffen (2008). Daten und Fakten zur Internationalität von Studium und Forschung in Deutschland. Bielefeld: Deutscher Akademischer Austauschdienst (DAAD).

Duff, A. 2002. Approaches to learning: Factor variance across gender. Personality and Individual Differences, 33(6): 9971110.

Entwistle, N. J., Hanley, M., \& Hounsell, D. 1979. Identifying distinctive approaches to studying. Higher Education, 8(4): 365-380. 
Freedman, R. D., \& Stumpf, S. A. 1978. What can one learn from the learning style inventory? Academy of Management Journal, 21(2): 275 .

Future is another country, The. 2009. The Economist, 390(8612): $43-44$.

Hanisch, D. A. 2003. Managementtraining in China: Neue Erkenntnisse über Akzeptanz und Relevanz westlicher Managementtheorien und Trainingsmethoden. Frankfurt a.M.: Peter Lang Verlag.

HESA. 2008. Key Points - Enrolments (All UK HEIs).

Hofstede, G. 1980. Culture's consequences. International differences in work-related values. Beverly Hills, CA: Sage.

Hofstede, G. 1994. Value Survey Module 1994 manual. University of Tilburg, Maastricht, The Netherlands: IRIC.

Hofstede, G. 2001. Cultures consequences: Comparing values, behaviors, institiutions and organizations across nations. Thousand Oaks, CA: London: New Delhi: Sage.

Honey, P., \& Mumford, A. 1992. The manual of learning styles. Maidenhead: Peter Honey Publications.

House, R. J., Hanges, P. J., Javidan, M., Dorfman, P. W., \& Gupta, V. 2004. Culture, leadership, and organizations. The GLOBE study of 62 societies. Thousand Oaks, CA: Sage.

Jackson, T. 1995. European management learning: A crosscultural interpretation of Kolb's learning cycle. The Journal of Management Development, 14(6): 42-50.

Jaju, A., Kwak, H., \& Zinkhan, G. M. 2002. Learning styles of undergraduate business students. A cross-cultural comparison between the US, India and Korea. Marketing Education Review, 12(2): 49-60.

Joy, S., \& Kolb, D. A. 2009. Are there cultural differences in learning style? International Journal of Intercultural Relations, l(33): 69-85.

Katz, N. 1988. Individual learning style, Israeli norms and crosscultural equivalence of Kolb's learning style inventory. Journal of Cross-Cultural Psychology, 19: 361-379.

Kayes, D. C. 2005. Internal validity and reliability of Kolb's Learning Style Inventory Version 3 (1999). Journal of Business and Psychology, 20(2): 249-257.

Keirsey, D. 1998. Please understand me II. Del Mar, CA: Prometheus Nemesis Book Company.

Kolb, A. Y., \& Kolb, D. A. 2005. Learning styles and learning spaces: Enhancing experiental learning in higher education. Academy of Management Learning and Education, 4(2): 193-212.

Kolb, D. A. 1976. Learning Style Inventory manual. Boston, MA.

Kolb, D. A. 198la. Experiential learning theory and the Learning Style Inventory: A reply to Freedman and Stumpf. Academy of Management Review, 6(2): 289-296.

Kolb, D. A. 1981b. Learning styles and disciplinary differences. Neddham Heights, MA.

Kolb, D. A. 1984. Experiential learning. Experience as a source of learning and development. Englewood Cliffs, NJ: Prentice Hall.

Kolb, D. A. 2000. Facilitator's guide to learning. Boston, MA: Hay/McBer.

Kolb, D. A., Rubin, I. M., \& McIntyre, J. M. 1984. Organisational psychology. An experiential approach. Englewood Cliffs, NJ: Prentice Hall.
Kruger, T., \& Roodt, G. 2003. Hofstede's VSM-94 revisitied: Is it reliable and valid? SA Journal of Industrial Psychology, 29(1): 75-82.

Lam, S. S. K. 1998. Organizational performance and learning styles in Hong Kong. Journal of Social Psychology, 138(3): 401-402.

Lawrence, M. 1997. Secondary school teachers and learning style preferences: Action or watching in the classroom? Educational Psychology, 17(1/2): 157-170.

Ledoux, J. 1999. The emotional brain: The mysterious underpinnings of emotional life. New York: Phoenix.

Mainemelis, C., Boyatzis, R. E., \& Kolb, D. A. 2002. Learning styles and adaptive flexibility. Testing experiential learning theory. Management Learning, 33(1): 5-33.

Manikutty, S., Anuradha, N. S., \& Hansen, K. 2007. Does culture influence learning styles in higher education? International Journal of Learning and Change, 2(1): 70-87.

McAdams, D. P., \& Pals, J. L. 2006. A new Big Five: Fundamental principles for an integrative science of personality. American Psychologist, 61(3): 204-217.

McKee, T. E., Mock, E. J., \& Ruud, T. F. 1992. A comparison of Norwegian and United States accounting students' learning style preferences. Accounting Education, 1(4): 321-341.

McSweeney, B. 2002a. The essentials of scholarship: A reply to Geert Hofstede. Human Relations, 55(11): 1363.

McSweeney, B. 2002b. Hofstede's model of national cultural differences and their consequences: $A$ triumph of faith - $A$ failure of analysis. Human Relations, 55(1): 89.

Morris, M. W., Leung, K., Ames, D., \& Lickel, B. 1999. Views from inside and outside: Intergrating emic and etic insights about culture and justice judgement. Academy of Management Review, 24(4): 781-796.

Myers, I. B., McCaulley, M. H., Quenk, N. L., \& Hammer, A. L. 2000. MBTI manual: $A$ guide to the development and use of the Myers-Briggs Type Indicator (3rd ed.). Washington, DC: Consulting Psychologists Press, Inc.

Nunnally, J. C. 1978. Psychometric theory (2nd ed.). New York: McGraw-Hill.

Peters, D., Jones, G., \& Peters, J. 2008. Preferred 'learning styles' in students studying sports-related programmes in higher education in the United Kingdom. Studies in Higher Education, 33(2): 155-166.

Ramburuth, P., \& McCormick, J. 2001. Learning diversity in higher education: A comparative study of Asian international and Australian students. Higher Education, 42(3): 333-350.

Schworm, P. 2008. Foreign students flock to the US. The Boston Globe.

Sewell, T. J. 1986. The measurement of learning style: A critique of four assessment tools. Green Bay: University of Wiscon$\sin$.

Smith, P. J., \& Sadler-Smith, E. 2006. Learning in organizations. Complexities and diversities. London, New York: Routledge.

Spector, P. E., Cooper, C. L., \& Sparks, K. 2001. An international study of the psychometric properties of the Hofstede values survey module 1994: A comparison of individual and countryprovince level results. Applied Psychology An International Review, 50(2): 269-281.

Thomas, A., \& Bendixen, M. 2000. The management implications 
of ethnicity in South Africa. Journal of International Business Studies, 31(3): 507.

Triandis, H. C. 1995. Individualism and collectivism. Boulder, CO: Westview Press.

Trompenaars, F. 1998. Riding the waves of culture: Understanding diversity in global business (2nd ed.). New York: McGrawHill.

UNESCO. 2008. EFA global monitoring report. Paris: UNESCO.

Yamauchi, L. A. 1998. Individualism, collectivism and cultural compatibility: Implications for counselors and teachers. Journal of Humanistic Education and Development, 36(4): 189-107.

Yamazaki, Y. 2005. Learning styles and typologies of cultural differences: A theoretical and empirical comparison. International Journal of Intercultural Relations, 29(5): 521-548.
Yamazaki, Y., \& Kayes, D. C. 2004. An experiential approach to cross-cultural learning: A review and integration of competencies for successful expatriate adaptation. Academy of Management Learning \& Education, 3(4): 362.

Ying, W. 2008. Record number of students to travel abroad. China Daily, 17.01.2008.

You, Z., \& Jia, F. 2008. Do they learn differently? An investigation of the pre-service teachers from US and China. Teaching and Teacher Education, 24(4): 836-845.

Yuen, C.-C., \& Lee, S. N. 1994. Learning styles and their implications for cross-cultural management in Singapore. Journal of Social Psychology, 134(5): 593.

Zull, J. 2002. The art of changing the brain: Enriching the practice of teaching by exploring the biology of learning. Sterling, VA: Stylus Publishing.

Dirk Holtbrügge ( $\mathrm{PhD}$ and habilitation, University of Dortmund) is professor of international management at the University of Erlangen-Nuremberg, Germany. His research interests include international and intercultural management, human resource management, and management in Asia and Eastern Europe.

Alexander T. Mohr (PhD and habilitation, University of Erlangen-Nuremberg) is professor in strategy and international business at Kent Business School, UK. His research focuses on the management of international joint ventures and issues related to international human resource management and intercultural management. 